\title{
Epidemiological Profile of High-Risk Pregnancies in Lubumbashi: Case of the Provincial Hospital Janson Sendwe
}

\author{
Kabamba Nzaji Michel'1, Banze Chris Ilunga², Katumbo Mukemo Astrid³, Ilunga Kahaki Blaise ${ }^{4}$, \\ Khaki Khang Mariette ${ }^{3}$, Kiluba Tshikala Pitchou ${ }^{3}$, Mudisu Kayinga Loriot ${ }^{3}$, \\ Nyembo Mukena Christiphe5, Mindje Kolomba6, Oscar Luboya Numbi ${ }^{7}$
}

\footnotetext{
${ }^{1}$ Department of Public Health, Faculty of Medicine, University of Kamina, Kamina, Democratic Republic of Congo

${ }^{2}$ Faculty of Medicine, University of Kamina, Kamina, Democratic Republic of Congo

${ }^{3}$ Nursing Sciences, Higher Institute of Medical Techniques of Lubumbashi, Lubumbashi, Democratic Republic of Congo

${ }^{4}$ Midwives, Higher Institute of Medical Techniques of Lubumbashi, Lubumbashi, Democratic Republic of Congo

${ }^{5}$ Department of Science Base, Faculty of Medicine, Lubumbashi University, Kamina, Democratic Republic of Congo

${ }^{6}$ General Hospital of Reference Kamina, Democratic Republic of Congo

${ }^{7}$ Department of Public Health and Pediatrics, Faculty of Medicine, Lubumbashi University, Lubumbashi, Democratic Republic of Congo

Email: michelnzaji@yahoo.fr
}

How to cite this paper: Michel, K.N., Ilunga, B.C., Astrid, K.M., Blaise, I.K., Mariette, K.K., Pitchou, K.T., Loriot, M.K., Christiphe, N.M., Kolomba, M. and Numbi, O.L. (2016) Epidemiological Profile of High-Risk Pregnancies in Lubumbashi: Case of the Provincial Hospital Janson Sendwe. Open Access Library Journal, 3: e3224.

http://dx.doi.org/10.4236/oalib.1103224

Received: November 10, 2016

Accepted: December 4, 2016

Published: December 7, 2016

Copyright $\odot 2016$ by authors and Open Access Library Inc.

This work is licensed under the Creative

Commons Attribution International

License (CC BY 4.0).

http://creativecommons.org/licenses/by/4.0/

\begin{abstract}
Maternal and child health is an important part in the health development plans in many countries. This descriptive study aimed to investigate the epidemiology of risk pregnancies managed at the provincial hospital Janson Sendwe. It was conducted from March 17 to July 15, 2015 to all pregnant women for childbirth consultant beyond 28 weeks of gestation and having at least one risk factor identified during antenatal care or a posteriori childbirth. On 535 women included in the study, we recorded 1667 risk factors in an average of 3.2 risk factors per woman. The three main risk factors were met by order of importance: the history of maternal infection (18.5\%), the history of caesarean section (13.6\%) and unexplained fetal or neonatal death antecedent $(12.4 \%)$. The antecedent of uterine malformation $(0.1 \%)$, the history of macrosomia $(0.5 \%)$ and uterine height decreased $(2.1 \%)$ were the least represented. It thus appears necessary to carefully monitor these women to avoid the occurrence of maternal mortality.
\end{abstract}

\section{Subject Areas}

Epidemiology, Gynecology \& Obstetrics

\section{Keywords}

Epidemiological Profile, High-Risk Pregnancy 


\section{Introduction}

Pregnancy is a normal, healthy state which most women aspire to at one time or another in their lives. However, this normal process and creator of life involve serious risk of death and disability. We often hear that in the world each year more than one million young women die from complications of pregnancy or childbirth, it is no longer shocks. Yet most of these deaths could be avoided if preventive measures were taken and if the care was available [1].

According to the definition, it is pregnancies in which the fetus and/or mother are at increased risk of mortality or morbidity, before, during or after birth. The hazard occurs to the mother by the worsening of a preexisting condition and the appearance of a new disease. For the fetus, this danger is threefold: prematurity; chronic fetal distress and intrauterine growth retardation and death in utero [2].

Maternal mortality is very high, which is unacceptable. Approximately 830 women die each day worldwide due to complications related to pregnancy or childbirth. In 2015, 303,000 women died during or after pregnancy or childbirth. Most of these deaths occurred in low-income countries, and most could have been prevented [3].

In sub-Saharan Africa, a number of countries have halved the rate of maternal mortality since 1990. In other regions, including Asia and North Africa, even greater progress has been made. Between 1990 and 2015, the global maternal mortality ratio (the number of maternal deaths per 100,000 live births) declined by only $2.3 \%$ per year. Nevertheless, the decline in maternal mortality has accelerated since 2000. In some countries, the annual decline in maternal mortality between 2000 and 2010 was located above $5.5 \%$, which is the required rate to achieve the Millennium development goals [4].

According to the WHO report, the DRC is among the eighteen countries worldwide where maternal mortality ratios are still very high with MMR estimates ranging between 500 and 999 deaths per 100,000 live births in 2015 and related to the attainment of the MDGs target 5A, the DRC is classified as "no progress" with changes in the MMR sawtooth (879 in 1990, 914 in 1995, 874 in 2000, 787 in 2005, 794 in 2010 and 693 in 2015). According to the survey population and health, the maternal mortality ratio is estimated at 846 deaths per 100,000 live births in the seven years preceding the survey [5].

In general, maternal mortality is still worrying in our country. Several factors have been implicated to explain this health distress. Women die from causes directly or indirectly related to pregnancy, childbirth or in the postpartum most of which are preventable. About $80 \%$ of deaths are due to direct causes; the four major causes: severe bleeding (mostly within the postpartum), infections (sepsis especially), hypertensive disorders in pregnancy (usually eclampsia) and obstructed labor; complications following abortions in poor conditions accounted for $13 \%$ of deaths. Among the indirect causes of maternal deaths (20\%), we must remember that there are diseases that complicate pregnancy or are aggravated during this period of life, such as malaria, anemia, HIV/AIDS, tuberculosis and unspecified chronic respiratory infections or cardiovascu- 
lar disease [6].

Birth for a woman is a source of respect and great hope for the family and for society. However, this event, which should be a source of happiness and collective joy can transform our regions into a tragedy because of the high rate of maternal death. 303,000 women died worldwide in 2015 from causes related to pregnancy and 15,000 women die each year in DRC giving life. Every 30 minutes, at least one woman dies in childbirth in DRC. Thus, the objective of our study was to evaluate the epidemiological profile of pregnancies at risk management at the provincial hospital Janson Sendwe.

\section{Material and Methods}

The study targeted women who viewed the Provincial Hospital of Reference Janson Sendwe. This is a retrospective descriptive study conducted from March 17 to July 15, 2015 to all pregnant women for childbirth consultant beyond 28 weeks of gestation and having at least one risk factor identified during prenatal consultation or subsequent to the time of delivery. These women were identified among those who come to give birth at the maternity hospital Provincial Janson Sendwe.

Were not considered in this study: the women who deliver at home and those who have not submitted a risk factor; A total of 1416 women who gave birth in maternity said were retained in the study.

The risk factors identified in our study are: 1$)$ factors related to the field: higher age or égal 35,2$)$ factors relating to the gynecological obstetric history: cesarean, multiparity (parity $>4$ ), low birth weight or fat kid (macrosomia), perinatal or neonatal death; 3 ) factors related to a pathology of pregnancy in progress: anemia, antepartum haemorrhage, premature rupture of membranes, multiple pregnancy.

Data collection was conducted from obstetric records found in the maternity ward, and supplemented by the antenatal records if the woman has consulted a center. Entry and data analysis were performed using SPSS 19.

\section{Results}

It appears from this table that $83.8 \%$ of women aged between 18 - 35 years, $78.1 \%$ had a gestational age less than 37 weeks of pregnancy, most women were less educated (76.5\%), $82.4 \%$ were married and $89.3 \%$ had an average socioeconomic level (Table 1 ).

According to the list of selected factors, we recorded 1667 risk factors among 535 women included in the study, an average of 3.2 risk factors per woman. The three main risk factors are encountered in order of importance: the history of maternal infection (18.5\% of risk factors), the history of caesarean section (13.6\% of risk factors) and history of unexplained fetal or neonatal death (12.4\% of risk factors). Excessive uterine height (10.8\% of risk factors), the history of low birth weight ( $9.7 \%$ risk factor), an antepartum haemorrhage ( $9.2 \%$ of risk factors) and multiple pregnancies $(8.6 \%$ of risk factors) come right after. The antecedent of uterine malformation ( $0.1 \%$ of risk factors), the history of macrosomia ( $0.5 \%$ of risk factors) and uterine height decreased $(2.1 \%$ of risk factors) were the least represented (Table 2). 
Table 1. General characteristics of women $(n=524)$.

\begin{tabular}{ccc}
\hline Age of woman & Effective & Percentage \\
\hline 18 to 35 & 439 & $83.8 \%$ \\
Inf to 18 & 10 & $1.9 \%$ \\
Sup to 35 years & 75 & $14.3 \%$ \\
Gestational age & & \\
Inf 37 SA & 409 & $78.1 \%$ \\
Sup 37 SA & 115 & $21.9 \%$ \\
Level of instruction & & $23.5 \%$ \\
Educated & 123 & $76.5 \%$ \\
Less educated & 401 & \\
Marital status & & $82.4 \%$ \\
Married & 432 & $17.6 \%$ \\
Low & 92 & $5.0 \%$ \\
High & & $5.7 \%$ \\
Socioeconomic level & 30 & 26 \\
\hline Unmarried (single, widowed, divorced) & 468 & \\
\hline
\end{tabular}

Table 2. Frequency and type of risk factors.

\begin{tabular}{cccc}
\hline Risk factors & Effective & $\begin{array}{c}\text { \% Total risk } \\
\text { pregnancies } \\
(\mathbf{n}=\mathbf{5 2 4})\end{array}$ & $\begin{array}{c}\text { \% Total risk } \\
\text { factors } \\
(\mathbf{n}=\mathbf{1 6 6 7})\end{array}$ \\
\hline Age $>$ 35 years & & $14.3 \%$ & $4.5 \%$ \\
Parity > & 75 & $7.6 \%$ & $2.4 \%$ \\
Abortion history repeating & 40 & $18.7 \%$ & $5.9 \%$ \\
History of uterine malformation & 98 & $0,2 \%$ & $0.1 \%$ \\
Multiple pregnancy & 1 & $27.3 \%$ & $8.6 \%$ \\
Maternal infection history & 143 & $59.0 \%$ & $18.5 \%$ \\
History of fetal or neonatal death unexplained & 309 & $39.3 \%$ & $12.4 \%$ \\
Previous Caesarean section & 206 & $43.3 \%$ & $13.6 \%$ \\
History of low birth weight & 227 & $30.7 \%$ & $9.7 \%$ \\
History of macrosomia & 161 & $1.5 \%$ & $0.5 \%$ \\
Antepartum haemorrhage & 8 & $29.2 \%$ & $9.2 \%$ \\
Premature rupture of membranes & 153 & $18.7 \%$ & $5.9 \%$ \\
Excessive HU & 98 & $34.4 \%$ & $10.8 \%$ \\
HU decreased & 180 & $6.7 \%$ & $2.1 \%$ \\
History of prematurity & 35 & $24.0 \%$ & $7.6 \%$ \\
Anemia & 126 & $17.7 \%$ & $5.6 \%$ \\
\hline
\end{tabular}


Table 3. Number of risk factors per woman.

\begin{tabular}{ccc}
\hline Many factors & Effective & Percentage \\
\hline 1 & 42 & $8.0 \%$ \\
2 & 143 & $27.3 \%$ \\
3 & 133 & $25.4 \%$ \\
4 & 108 & $20.6 \%$ \\
5 & 81 & $15.5 \%$ \\
6 & 16 & $3.0 \%$ \\
7 & 1 & $0,2 \%$ \\
Total & 524 & $100.0 \%$ \\
\hline
\end{tabular}

Furthermore, $27.3 \%$ of women had two risk factors; $25.4 \%$ had three factors and $20.6 \%$ had more than four risk factors. $8.0 \%$ of women had only one risk factor and $0.2 \%$ of women had seven risk factors (Table 3 ).

\section{Discussion}

In this study, the majority of mothers were in the group of 18 - 35 years (83.8\%) of age. Our results corroborate those in the literature, such a study of Mukhopadhyay et al. which found that teenage mothers had a higher proportion of premature births compared to adult mothers and had low weight at birth of baby [6].

We observed 1416 deliveries and have considered 524 (37.0\%), to be associated with women having at least one risk factor. A prevalence of $31.4 \%$ was found by Bharti in Haryana [7]. A hospital study by Akhtar et al. at Bangladesh has found an incidence of $4.52 \%$. Among these patients, $69.5 \%$ lived in rural areas [8]. In another study by Mufti et al., (2008) in Kashmir, the incidence of high-risk pregnancies has been reported at 15\% (2008 Mufti et al.). In fact, the rate of pregnancies at risk is relatively low compared to other studies, such as those of Jahn et al. who found that in Nepal a proportion of $41.5 \%$ on all consultants [5] Al Teheawy who found a rate of $46.2 \%$ in Saudi Arabia, however, it is higher than that found in Cameroon, or 21\% between [7] 1982 and 1985, and that observed in Belgium, which is $21.8 \%$ in 2005 [8] and $27.7 \%$ in Alexandria (Egypt). A study conducted in the city of Taif, Saudi Arabia, revealed that $63.3 \%$ of the sample had a high-risk pregnancy at risk, and $63.8 \%$ in the study of Yassein et al. in Egypt [9]. In developing countries over $50 \%$ of pregnant women with high risk pregnancies were living in rural areas. This variability in prevalence can be attributed to the difference in the regions, populations, methods, diagnostic criteria and definitions used so that the true comparison between them is not really feasible for practical reasons and cannot give a very clear picture of the real situation.

We recorded 1667 risk factors among 524 with a risk pregnancy, an average of 3.2 risk factors per woman, much higher result than that of Bouafia Tunisia [10]. In this study we found that $92.0 \%$ of women had at least one risk factor. A study among 330 pregnant women in Niger in 2000 showed that 55\% had only one risk factor and 31\% two or more. These results are much lower than ours. Indeed, it is rare that the woman 
has a single risk factor; generally, several factors coexist and their combination worsens the prognosis, thus the importance of prenatal care and especially the first prenatal visit.

The three main risk factors found in this study were of maternal infection history, caesarean section and unexplained fetal or neonatal death. A study in Egypt showed three factors also: age greater than 35 years, a greater than or equal to 5 parity and anemia [11].

For Akhtar, preeclampsia, hypertension induced by pregnancy and gestational diabetes were the main risk factors [8]. Note that when a woman has a problem during pregnancy, such as premature birth, birth defects, the history of abortion, stillbirth, or previous Caesarean section, she will be more likely to have a same problem in subsequent pregnancies.

The history of cesarean section or more is found in $43.3 \%$ of our patients. This proportion is much higher than that observed in the Al Hassa Saudi Arabia (5.8\%) [12]. Lower rates were reported in the literature [2]. In relation to age, $14.3 \%$ of women in our study were older than 35 years. Forty percent of Saudi pregnant women had a higher risk because of their age 35 [9]. It is generally accepted that women over 35 have an increased risk of complications during pregnancy. However, the most reported factors related to age are hypertension, diabetes, parity, uterine myoma, preeclampsia and fetal chromosomal abnormalities. Each of them being associated with a higher risk of emergency caesarean section, which is associated with a higher risk of bleeding and infection.

\section{Conclusion}

Maternal and child health is an important part in the health development plans of many countries including the Democratic Republic of Congo. This study aimed to investigate the epidemiology of risk pregnancies. It was noted that in 1667 the risk factors were identified among 535 women, an average of 3.2 risk factors per woman. The three main risk factors encountered were the antecedent of maternal infection (18.5\%), the history of caesarean section (13.6\%) and unexplained fetal or neonatal death history (12.4\%). Moreover, almost a third of women had two risk factors, whereas $0.2 \%$ had seven risk factors. At this level, in terms of priorities, we must not forget that the most efficient measure to reduce this risk is not as much the promotion of prenatal care with known limitations, but much more that of midwifery; that's to say at the time of childbirth but also to emphasize the need to better equip maternity draining the highest proportion of women at risk. But for health policy makers and in terms of priorities, we must not forget that the most efficient measure to reduce this risk is not as much the promotion of prenatal care with known limitations, but that much more care obstetric; that is to say at the time of delivery and that the various levels of care.

\section{References}

[1] Abdourhamane, Mr. (2008) Study of Maternal Mortality in the Obstetrics and Gynecology 
Department of CHU Gabriel Touré: From Epidemiology to the Audit. University of Bamako.

[2] Mamadou Kone, T. (2008) High-Risk Pregnancies in the Reference Center of Bougouni about 110 Cases. University of Bamako.

[3] WBG and the UNPD UNICEF, WHO, UNFPA (2015) Trends in Maternal Mortality: 1990 to 2015 .

[4] UNICEF, WHO, World Bank, UN-DESA Population Division (2013) Levels and Trends in Child Mortality.

[5] Ministry of Planning (2014) Demographic and Health Survey 2013-2014.

[6] Jain, S., Anand, S. and Aherwar, R. (2014) High Risk Scoring for Prediction of Pregnancy Outcome: A Prospective Study. International Journal of Reproduction Contraception, $\mathrm{Ob}$ stetrics and Gynecology, 3, 516-522. https://doi.org/10.5455/2320-1770.ijrcog20140910

[7] Bharti, Mr., Kumar, V., Kaur, A. and Chawla, S. (2016) Prevalence and Correlates of High Risk Pregnancy in Rural Haryana: A. International Journal of Basic and Applied Medical Sciences, 3, 212-217.

[8] Akhtar, H., Sultana, S. and Siddique, A. (2009) Come in out Neonatal High Risk Pregnancy. The Journal of Teachers Association, 22, 26-29.

[9] Hafez, S.K., Dorgham, L.Sh. and Sayed, S.A.M. (2014) Profile of High Risk Pregnancy among Women in Saudi Taif-KSA. World Journal of Medical Sciences, 11, 90-97.

[10] Bouafia, N., Mahjoub, Mr., Nouira, A., Ben Aissa, R., Saidi, H. and Njah, N.G.M. (2013) Epidemiological Profile of High-Risk Pregnancies in Sousse (Tunisia). EMHJ, 19, 465-473.

[11] Kashani, E., Hassanzad, A. and Ameri, M.A. (2012) The Rate of the Prevalence of HighRisk Pregnancies and the Results on Pregnant Mothers and the Effect on Parameters after the Birth. Advances in Environmental Biology, 6, 1319-1324.

[12] Al Teheawy, M.M. (1992) Prenatal Care in Primary Health Care Centers of Al-Hasa, Saudi Arabia. Journal of the Egyptian Public Health Association, 67, 37-51.

\section{Submit or recommend next manuscript to OALib Journal and we will provide best service for you:}

- Publication frequency: Monthly

- 9 subject areas of science, technology and medicine

- Fair and rigorous peer-review system

- Fast publication process

- Article promotion in various social networking sites (LinkedIn, Facebook, Twitter, etc.)

- Maximum dissemination of your research work

Submit Your Paper Online: Click Here to Submit

Or Contact service@oalib.com 